\title{
Relationship between driver's record and automobile versus child pedestrian collisions
}

\author{
Amy S Lightstone, Corinne Peek-Asa, Jess F Kraus
}

\begin{abstract}
Objectives-The purpose of this study was to explain the relationship of a history of driver's violations as a factor in motor vehicle versus child pedestrian injury incidents.
\end{abstract}

Methods-A case-control study was conducted utilizing police reports from 1 January 1993, to 30 June 1995, to identify drivers (cases) whose car struck a child pedestrian less than 15 years of age. Controls were randomly selected drivers identified from the license files of the California Department of Motor Vehicles (DMV) who had no record of striking a child pedestrian in the 30 month study period. Two controls per case were selected based on postal code of residence and incident date of case. Prior driver citations, safety violations, license suspension/revocation, and negligent operator points were analyzed from 1 April 1991, to the incident date for cases and controls.

Results-Of 327 drivers who met the case definition, 237 (73\%) had information on file in the California DMV driver records. Analysis was based on 237 cases and 474 controls. Drivers who hit a child pedestrian were more likely to have had a prior citation, more citations, more safety violations, a suspended or revoked license, or more negligent operator points than drivers who did not hit a child pedestrian in the study period. A positive association exists between the number of citations, safety violations, or negligent operator points and the likelihood that a driver hit a child pedestrian.

Conclusions-Drivers with a history of driving infractions represent a high risk source of danger to child pedestrians. Possible routes of intervention include more rigorous sanctions against these drivers, more intensive education of the involved driver regarding pedestrians, higher insurance and monetary penalties, and a need to pursue more rigorously hitand-run and unlicensed drivers, including modification of driver code violations for such cases.

(Injury Prevention 1997; 3: 262-266)

Keywords: motor vehicle driver; driver history; child pedestrian; traffic.

Motor vehicle collisions with children are a significant cause of morbidity, mortality, and potential years of life lost. ${ }^{1}$ In 1994 , children under the age of 15 accounted for $32.1 \%$ of the pedestrian victims reported to the police in
California. ${ }^{1}$ Nationally, the 1994 fatality rate for pedestrians $0-15$ years of age was 1.32 per 100000 per year and the non-fatal injury rate was over 30 times higher at 41 per 100000 per year. ${ }^{2}$ Although many studies have addressed ${ }^{\infty}$ risk factors for pedestrians and a few studies $\vec{\circ}$ have evaluated the environment, little investi- $-\vec{\omega}$ gation has been conducted on driver charac- $\omega$ teristics, and even less has been publishedō recommending interventions aimed at the driver who strikes a child pedestrian.

In 1971, Snyder and Knoblauch published an model outlining behavioral characteristics of pedestrians and drivers that may lead to acollision or may help in its avoidance. ${ }^{3}$ When

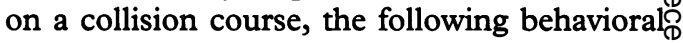
sequence exists: search, detect, evaluate, de- $\bar{B}$ cide on avoidance maneuver, and act. If either黑 the driver or the pedestrian is able to complete this sequence, then a collision is avoided. ${ }^{4}$ In 6 1985 , Rivara and Barber found that in $21 \%$ of the pedestrian collisions studied, there waso some fault on the part of the driver that contributed to the collision. ${ }^{5}$ Rivara concluded, in 1990, that the driver's failure to identify and correctly judge the pedestrian's action was found to be a factor in nearly one third of pedestrian-motor vehicle collisions. ${ }^{6}$

Howarth found that drivers leave most of the responsibility for avoiding collisions to thepedestrian. ${ }^{7}$ This conclusion was based on (1) subjective observations of driver and pedes trian behavior that showed that drivers do not take avoidance actions until the pedestrian is closer than the stopping distance of the vehicle; and (2) radar measurements of vehicles outside? of school entrances that showed no speed reduction when children are waiting to cross the street. A similar observation was documen-o ted by Katz et al who noted that drivers' actions in the presence of a teenage or young adult? pedestrian entering the roadway is almost never defensive ${ }^{8}$; that is, $86 \%$ of the drivers on residential streets failed to slow to a speed 0 that was within their stopping distance of the pedestrian. ${ }^{4}$

An important factor possibly related to ${ }_{\sigma}^{\omega}$ driver behavior is their driving history. Baker et al found driver negligence in $46 \%$ of all: pedestrian fatalities. ${ }^{9}$ In addition, $58 \%$ of the drivers who were considered negligent had at 'poor' driving record, defined as having aO

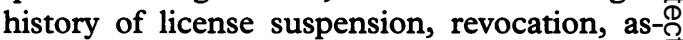
signment to driver rehabilitation clinic, con- $-\mathbb{Q}$ viction for drunk driving at any time before theo crash, or a history of traffic convictions for two or more separate events during the three yearso before the fatality. The lack of a comparison group of non-collision involved drivers as well? as the results being based solely on data from police reports and no driver history files, unfortunatley limited the value of this finding. 
Hit-and-run incidents complicate any attempt to study driver behavior in pedestrian incidents. Studies show that hit-and-run incidents range from $11.6 \%$ in California in $1994^{1}$ to $19 \%$ in the US (excluding Alaska and Hawaii) during 1989 and $1990^{10}(13 \%$ in Baltimore City from 1968 to $1971^{9}$ and $15 \%$ in Memphis in $1982^{5}$ ). Solnick and Hemenway studied drivers involved in pedestrian fatalities by comparing those who remained at the scene with those ultimately identified as hit-and-run drivers. ${ }^{10}$ They found that the hit-and-run motorists were more likely to have had a previous arrest for driving while intoxicated and were more likely to have a positive blood alcohol concentration. Hit-and-run drivers were also more likely to be driving with an invalid or suspended license. ${ }^{10}$

The objective of this study was to measure the relationship between previous driving violations and child pedestrian incidents.

\section{Methods}

A case-control design was used to compare previous driving violations among drivers involved in child pedestrian collisions (cases) and a sample of drivers not involved in any child pedestrian collisions during the study period (controls). A case was defined as any California licensed driver, who, while operating a motor vehicle on a street, highway, or public roadway in the city of Long Beach, struck a child pedestrian less than 15 years of age resulting in an injury and a police report. Those drivers posessing a California license but residing outside of Long Beach were included, but those drivers licensed by states other than California were excluded as driver histories could not be obtained. Long Beach city police reports were searched for events from 1 January 1993 through 30 June 1995 to identify eligible cases. Incidents involving unlicensed drivers or hit-and-run cases were also ascertained, but could not be included in the case series because driver histories did not exist. From the driver license number noted on the police reports driving histories were obtained from the California Department of Motor Vehicles (DMV).

A control was defined as any California licensed driver who had no record of striking a child pedestrian (under the same criteria as for the case) during the same study period. Controls were selected in the following way: From the DMV research files, a $1 \%$ random sample of California licensed drivers was provided by postal code. This was further truncated so that two control drivers for each case driver were randomly selected, resulting in a database with similar distributions of postal code of residence for case and control drivers and each case was matched to two controls by incident/reference date.

Information collected about each driver included age and gender. For the period from 1 April 1991, to the incident/reference date, the number of previous citations (multiple violations can occur on one citation), license revocations and/or suspensions, the number of officer cited safety violations (for example, violations pertaining to the vehicle, such as a broken tail light, expired registration), and negligent operator points (used by the DMV as an indicator of driver responsibility) were collected. A major driving conviction, such as driving under the influence, reckless driving, or hit-and-run, is generally assigned two points; a minor conviction (speeding, right of way, etc) is usually assigned one point. Convictions for violating multiple sections of the Vehicle Code that appear on the same citation do not increase the number of points assigned. A conviction is assigned point(s) based on the most serious violation. A crash is assigned one point when the driver is found by the investigating officer to have been at least partly responsible. Additionally, for the cases, information on the driver's blood alcohol concentration and other violations at the time of the incident were abstracted from the police reports.

Police reports for the case drivers were also reviewed for information on the nature of the collision. Comparisons of driver histories of the cases and that of controls were based on information from the DMV driver license files.

Data were analyzed utilizing a logistic regression model to derive adjusted odds ratios to control for the possible confounders of age and sex of the driver. Outcome variablesprior citation, safety violations, suspended/ revoked license, and negligent operator points - are interdependent and obscure independent effects when entered in the same model. Therefore, separate logistic models were used that controlled for age and sex.

\section{Results}

A search of 445 police reports of vehicle versus child pedestrian incidents from 1 January 1993 to 30 June 1995 (four were from drivers who were not licensed by the state of California), yielded 327 reports that occurred while a California licensed driver was operating a motor vehicle on a street, highway, or public roadway in the city of Long Beach and struck a pedestrian less than 15 years of age. Of the 327 drivers identified, information from the California DMV was obtained for 237 (73\%) of the cases. Of the 90 cases without available driver information, 77 (86\%) were hit-and-run incidents (only two of which were later identified, and neither possessed a valid driver's license). Twelve of the remaining 13 did not have a valid driver's license, did not have a license in their possession, or had a suspended license. One case occurred the day before the police report was filed by the pedestrian, and the driver was not contacted. Of the 237 cases with available driver histories, five were classified as hit-and-run incidents (by the police), for a total of $82(25 \%)$ hit-and-run incidents.

Of the 237 cases with DMV records, 65\% were males and $35 \%$ were females. From eyewitnesses and other information, it was determined that of the 90 cases without DMV information, $62 \%$ were males, $19 \%$ were females, and $19 \%$ could not be identified. Of 
the 474 controls, $58 \%$ were males and $42 \%$ were females $\left(\chi^{2}=3.8, p=0.05\right)$. The marginally significant difference in gender between cases and controls can be the result of non-differential bias by gender. The age range for the 237 cases was $14-87$ years and for the 474 controls was 16-95 years (table 1 ).

Of the 237 drivers who hit a child pedestrian, $197(83 \%)$ had a valid driver's license at the time of the incident. An invalid license is defined as being unlicensed (but may possess an identification card) or having a license which is suspended, revoked, canceled, or expired at least 90 days. Of the 40 (17\%) drivers cited for having an invalid license, 24 were considered unlicensed and 16 were driving with a suspended or revoked license. The vehicles of $73(31 \%)$ of the drivers were not insured at the time of the incident. Fifty $(21 \%)$ of the drivers were not residents of the city of Long Beach.

The driver was found to be the party at fault in $17 \%$ of the collisions but was issued a citation in only $57 \%$ of the events in which the driver was considered by the police to be at fault. When a secondary violation related to the

Table 1 Driver cases and controls by age, Long Beach, California

\begin{tabular}{lcc}
\hline Age & Case (\%) & Controls (\%) \\
\hline$<21$ & 7 & 6 \\
$21-30$ & 27 & 27 \\
$31-60$ & 57 & 57 \\
$60+$ & 9 & 10 \\
\hline
\end{tabular}

$\chi^{2}=0.8, \mathrm{p}=0.85$.

Table 2 Number of driver violations as the primary collision factor at the time of the incident

\begin{tabular}{lccc}
\hline Violation & Cited & Not cited & Total \\
\hline $\begin{array}{l}\text { Driver did not stop at limit line } \\
\text { at red light }\end{array}$ & 1 & 1 & 2 \\
$\begin{array}{l}\text { Driver must yield to pedestrian } \\
\text { Driver must not pass vehicle }\end{array}$ & 18 & 10 & 28 \\
$\quad \begin{array}{l}\text { stopped for pedestrian } \\
\text { Unsafe backing }\end{array}$ & 1 & 1 & 1 \\
$\begin{array}{l}\text { Unsafe turning } \\
\text { Speeding }\end{array}$ & 0 & 1 & 1 \\
$\begin{array}{l}\text { DUI of alcohol or drugs } \\
\text { DUI of alochol or drugs and } \\
\text { causing injury }\end{array}$ & 0 & 2 & 1 \\
Total & 0 & 1 & 1 \\
& 23 & 17 & 4 \\
\hline
\end{tabular}

DUI=driving under the influence.

Table 3 Number of other driver violations associated with and/or cited at the time of the incident

\begin{tabular}{lccc}
\hline Violation & Cited & Not cited & Total \\
\hline Hit-and-run & 4 & 1 & 5 \\
Unsafe passing & 0 & 1 & 1 \\
Speeding & 0 & 4 & 4 \\
DUI of alochol or drugs & 1 & 1 & 2 \\
$\quad$ and causing injury & 1 & 0 & 1 \\
$\begin{array}{l}\text { Possession of marijuana or } \\
\text { open container while driving }\end{array}$ & 1 & 0 & 1 \\
$\begin{array}{l}\text { Arrested for DUI } \\
\text { Child passenger not in }\end{array} \quad 1$ & 0 & 1 \\
carseat & 1 & 0 & 1 \\
Tnrelated to accident'^ & 1 & 7 & 14 \\
\hline
\end{tabular}

*Violations unrelated to the incident.

Only violations related to the incident are included.

DUI = driving under the influence. incident was noted, drivers were cited only $50 \%$ of the time (tables 2 and 3 ). Other factors related to the incident include driver inattention $(10 \%)$ and vision obscurement $(19 \%)$. Six drivers had been drinking, and three were determined to be under the influence of. alcohol.

Drivers who hit a child pedestrian were $3.9 \stackrel{\text { की }}{9}$ times $(95 \%$ confidence interval $(\mathrm{CI})=2.8$ to등 5.4) more likely to have a history of citations $\overline{\bar{\sigma}}$ than drivers in the comparison group. In $\mathbb{\nabla}$ addition, drivers who hit a child pedestrian were 1.5 times (95\% CI=1.3 to 1.8 ) more $^{\infty}$ likely to have a history of safety violations, 1.6. times $(95 \% \mathrm{CI}=1.1$ to 2.4$)$ more likely to have $\overrightarrow{\vec{H}}$ had a suspended or revoked license, and $1.9 \%$ times $(95 \% \mathrm{CI}=1.6$ to 2.3$)$ more likely to have a history of negligent operator points compared with controls. These variables were analyzedin independent of one another as correlation was N found among them (table 4).

A positive association was found betweenthe number of prior citations and the likelihood of a driver striking a child pedestrian. When $\varnothing_{\varnothing}$ controlling for age and sex of the driver, there 3 is an increased odds of a driver-child pedes-田 trian collision for drivers who have a history of $\vec{\bullet}$ an increased number of prior citations (figure). Drivers with one prior citation are 3.0 times $(95 \% \mathrm{CI}=2.1$ to 4.5$)$ more likely to hit a childO pedestrian, with increasingly larger odds ratios for drivers with five or more citations who are

Table 4 Driver history factors and risk of child pedestrian incidents adjusted odds ratios and $95 \% \mathrm{CI}^{\star}$

\begin{tabular}{ll}
\hline Variable & Odds ratio (95\% CI) \\
\hline Prior citation & $3.9(2.8$ to 5.4$)$ \\
Safety violations & $1.5(1.3$ to 1.8$)$ \\
Suspended/revoked license & $1.6(1.1$ to 2.4$)$ \\
Negligent operator points & $1.9(1.6$ to 2.3$)$ \\
\hline
\end{tabular}

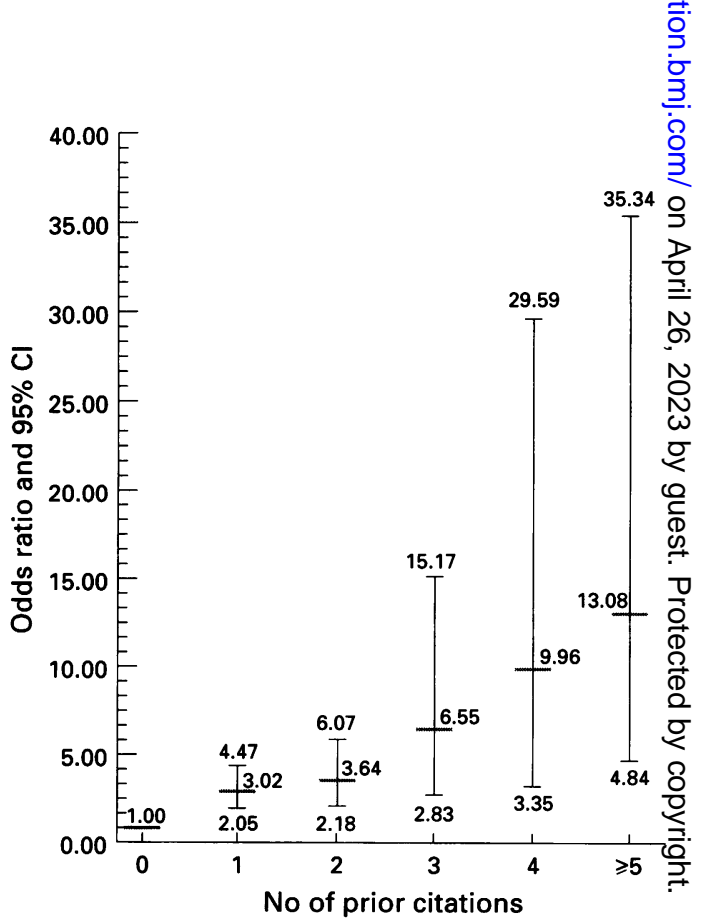

Number of prior citations and odds ratios and 95\% CI (adjusted for driver age and sex). 
Table 5 Number of safety violations and the effect of the number of negligent operator points odds ratios and $95 \% \mathrm{CI}^{*}$

\begin{tabular}{lll}
\hline & Odds ratio & $95 \%$ CI \\
\hline $\begin{array}{ll}\text { No of safety violations: } \\
0\end{array}$ & 1.0 & \\
1 & 1.9 & 1.3 to 2.8 \\
2 & 2.2 & 1.2 to 3.9 \\
3 & 5.2 & 2.0 to 13.5 \\
$\geqslant 4$ & 7.7 & 3.7 to 16.1 \\
No of negligent operator points: & \\
0 & 1.0 & \\
1 & 1.9 & 1.3 to 2.9 \\
2 & 4.3 & 2.4 to 7.7 \\
$\geqslant 3$ & 5.1 & 2.6 to 10.2 \\
\hline
\end{tabular}

^Note: adjusted for driver age and sex.

13.1 times $(95 \% \mathrm{CI}=4.8$ to 35.3$)$ more likely to strike a child pedestrian (table 5). Drivers with one safety violation are 1.9 times $(95 \% \mathrm{CI}=1.3$ to 2.8 ) more likely to be involved in a child pedestrian collision, while drivers with four or more safety violations are 7.7 times (95\% $\mathrm{CI}=3.7$ to 16.1 ) more likely to strike a child pedestrian compared with drivers from the comparison group. Similarly, drivers with one negligent operator point are 1.9 times (95\% $\mathrm{CI}=1.3$ to 2.9 ) more likely to hit a child pedestrian, and those with three or more negligent operator points are 5.1 times (95\% $\mathrm{CI}=2.6$ to 10.2 ) more likely to strike a child pedestrian compared with drivers from the control group.

\section{Discussion}

Vehicle collisions with child pedestrians is a significant and unresolved public health problem. Evaluating the history of drivers who strike these children is one means of finding possible routes for intervention. Results of this investigation suggest that drivers having prior citation(s) or a suspended/revoked license are risk factors. Furthermore, as the number of previous citations, safety violations, or negligent operator points issued increases, so does the risk. Although these variables are interrelated, the patterns clearly show that drivers who strike a child pedestrian are much more likely to have poor driving histories. And, with more violations, the risk increases compared with non-incident drivers.

In an independent study, the California DMV found that the greater number of traffic convictions accumulated by drivers, the more likely these drivers are to be involved in all types of collisions. ${ }^{11}$

It appears that officers do not consistently cite drivers who are at fault (only $57 \%$, or less, of the time). Citing drivers at the time of the incident, as well as taking more severe action against drivers with a history of traffic citations and/or safety violations (such as impounding their vehicle) may help reduce child pedestrian incidents in the future.

Greater penalties for drivers who are unlicensed or driving with a suspended or revoked license may be an important intervention. Although controversial, random checks to verify drivers' licenses, with consequential penalties both for the individual not possessing a valid driver's license (an arrest) as well as for the owner of the vehicle (impounding the vehicle) may help deter unlicensed or suspended/revoked licensed drivers from driving. The San Francisco Police Department has implemented a successful program that allows the court to impound for $\mathbf{3 0}$ days the vehicles of drivers who are unlicensed or driving with a suspended or revoked license. During the first year of the program (1995) the results showed a $26 \%$ reduction in total fatal and injury collisions, and a $25 \%$ reduction in hit-andrun collisions. ${ }^{12}$ New laws that impound the vehicle of unlicensed drivers also may be effective. In addition, increasing the scope of driver training for those receiving violations (traffic school) and driver education to include pedestrian safety awareness, may be beneficial. Ehret has suggested that withdrawal of the driver's license is a necessary, but not sufficient condition to change behavior. ${ }^{13}$ Included in the withdrawal of the driver's license is the offer of traffic psychological counseling so that the time without a driver's license can be used toward problem solving.

A significant problem identified in this study is the hit-and-run driver. Hitting a child pedestrian is serious, but then to flee the scene is a much more serious offense. These drivers fall into one of the following categories: the driver may have been at fault for the collision and does not want to take responsibility; the driver may have been intoxicated or have had a previous arrest for driving while intoxicated; the driver may not have a valid driver's license; the driver may have been trying to avoid the law for some reason unrelated to the incident; or the driver may have been unaware of hitting a pedestrian. Apprehending these drivers would significantly help in the identification of risk factors pertaining to the driver, because they comprised $25 \%$ of the incidents. A campaign to obtain citizens' help in apprehending hit-and-run drivers could be an effective strategy as there are often witnesses to the incidents. Media campaigns to expand citizen awareness have proven successful in the past, as demonstrated in the pedestrian safety program in the Victoria (Canada) metropolitan area where multimedia campaigns have targeted drivers producing a long term effect of increasing drivers' yielding behaviors. ${ }^{14}$ In addition, alerting the public that fleeing after the scene of a collision is illegal may also help reduce hit-and-run events. Another strategy is to increase police surveillance, especially at high risk locations where hit-and-run incidents occur.

This study was limited by being able to only include as a case those drivers who possessed a driver's license (valid or invalid). Drivers who were unlicensed could not be included as it would be impossible to obtain driving histories. Similarly, it was not possible to include hitand-run incidents where the driver was never apprehended as, again, no driver histories were available. A second limitation was that since the data source was the California DMV, only California licensed drivers could be included. This probably did not alter the outcome as only four incidents involved drivers licensed in 
other states that were excluded. The use of police reports to ascertain cases has the limitation that in order to become a case, a police report must have been generated. There appears to sometimes be failure of the involved parties to notify the police. Perception by the public of such incidents as injury events, as opposed to reportable motor vehicle collisions, is probably a major contributor to this phenomenon. Pedestrian incidents involving children 4 years old and younger may be underreported. ${ }^{15}$ This may also be due to a severity bias in that, if the pedestrian is minimally injured or uninjured, the parties involved may be less likely to contact the police; especially, as the child is usually scared and upset after such an incident and does not know that contacting the police is an option. The final limitation is that cases were identified from 1993-5, whereas controls were randomly selected from the DMV database in 1996. The assumption is that the drivers in the 1996 database are a representative sample of drivers and that they are homogeneous with the drivers from 1993-5. The premise is made that the driver characteristics are similar throughout 1993-6, and that reporting of cases to the police did not change during the study period. As with all case-control studies relying on existing records, it is unknown whether or not these limitations impact the results.

Further research trying to delineate information regarding unlicensed drivers and drivers involved in hit-and-run incidents is important to attempt intervention. Ascertaining specific types of violations and considering driver experience as a potential variable or risk factor would be beneficial. Also important is to determine possible methods of enforcement once risk factors have been identified.
The authors wish to thank the following for their help and contributions in this study: Ray Peck and Mike Gebers from the Conifucion the California Department of Motor Vehicles; Peter Corpuz and Linda Thompson of the Long Beach Department of Public
Works; John Kile and Medical Records staff at St Mary Medical Center; and Patty Conn at Long Beach Memorial Hospital. This work was supported by the Southern California Injury $T$ Prevention Research Center, a CDC funded national research center (grant \#CCR903622). tatewide Integrated Traffic Records System. 1994 Annual report of fatal and injury motor vehicle trafjic collision. $\mathbb{\mathbb { D }}$ California: Departme

2 National Highway Traffic Safety Administration. Traffic है safety facts 1994. Washington: US Department of Trans- $\overrightarrow{0}$ portation, NHTSA, August 1995.

3 Snyder MB, Knoblauch RL. Pedestrian safety: the identification of precipitating factors and possible countermeasures. $\vec{\omega}$ Washington: US Department of Transportation, National Highway Traffic Safety Administration. Vol 2. FH-117 312, 1971.

4 Malek M, Guyer B, Lescohier I. The epidemiology and prevention of child pedestrian injury. Accid Anal Prev. 1990; 22: 301-13. pedestrian injury. Accid Anal Prev

5 Rivara FP, Barber M. Demographic analysis of childhood N pedestrian injuries. Pediatrics 1985; 76: 375-81.

6 Rivara FP. Child pedestrian injuries in the United States. Am $\mathcal{F}$ Dis Child 1990; 144: 692-6.

7 Howarth I. Interactions between drivers and pedestrians: some new approaches to pedestrian safety. In: Evans L, Schwing RC, eds. Human behavior and traffic safety. Newळ York: Plenum Press, 1985: 171-85.

$8 \mathrm{Katz}$ A, Zaidel D, Elgrishi A. An experimental study of driver and pedestrian interaction during the crossing conflict. Hum Factors 1975; 17: 514-27.

9 Baker SP, Robertson LS, O'Neill B. Fatal pedestrian $\overrightarrow{0}$ collisions-driver negligence. Am f Public Health 1974 ; 64: $318-25$.

10 Solnick SJ, Hemenway D. Hit the bottle and run: the role of alcohol in hit-and-run pedestrian fatalities. $₹$ Stud Alcohol alcohol in hit-and-run pedestrian fatalities. F Stud Alcohol 1994; 55: $679-84$.

11 Gebers MA. Traffic conviction and accident-record facts. CALDMV-RSS-90-127, Sacramento, CA: California Depart-ฏ ment of Motor Vehicles, October 1990

12 San Francisco Police Department. STOPS. Unlicensed drivers. Sacramento, CA: OTS Tracks, 1996; 12(2): 1 - 3. 13 Ehret J. Revoking the driver's license-ingenious discoveryô

14 Koenig DJ, Wu Z. The impact of media campaign in the reduction of risk-taking behavior on the part of the drivers. Accid Anal Prev 1994; 26: 625-33.

15 Agran PF, Castillo DN, Winn DG. Limitations of data compiled from police reports on pediatric pedestrian and bicycle motor vehicle events. Accid Anal Prev 1990; 22: $361-70$.

\section{Skate boy is hurt 'hitching a lift' on bus}

A boy out roller blading was seriously injured while copying a scene from the film Back to the Future. Anthony Ball, 13, who grabbed hold of the back of a bus to hitch a lift up a hill, lost his grip and careered into the path of an oncoming van. He was the latest victim of the craze of bus surfing, inspired by a scene in Back to the Future in which Michael J Fox holds onto a vehicle while skate boarding. Anthony received injuries to his head, pelvis, and ribs in the weekend accident near his home in Quinton, Birmingham. Police said it happened as the bus rounded a bend, swinging Anthony outwards. As he lay critically ill in hospital, the Royal Society for the Prevention of Accidents pleaded for parents to warn children against the dangerous craze (Daily Mail (London), July 1997).

\section{Sporting injury?}

A cheeky couple had to be prised apart by dentists in Copenhagen after the braces on their teeth became locked together during a visit to the cinema! It took over two hours before the experts could release the pair from their embarrassing em-brace (sic). They probably won't kiss and tell! (Sunday Times (London), August 1997). 